\title{
Growth of a temperate coral: effects of temperature, light, depth, and heterotrophy
}

\author{
Margaret Wohlenberg Miller*
}

University of North Carolina at Chapel Hill, Institute of Marine Sciences, Morehead City, North Carolina 28557, USA

\begin{abstract}
The effects of temperature, light, food availability, depth, and season on growth and chlorophyll $a(\mathrm{chl}$ a) concentration in the temperate scleractinian coral Oculina arbuscula were experimentally examined in the laboratory and field. The coral has a wide temperature tolerance, but growth was significantly greater at summer than at winter temperatures. Light and a zooplankton food source both contributed significantly to chl a concentrations and to coral growth, with effects on growth being approximately additive. In both lab and field assays, growth and chl a concentrations at the end of the experiment had identical rankings among treatment means, suggesting that increased colony growth may be linked to increased concentrations of chl $a$. In the field, corals grew significantly better in shallow than in deep water when competing seaweeds were removed. However, coral distribution at 2 sites was concentrated in deeper, darker waters where growth should be slower, rather than in shallower areas where growth potential is higher. Thus, $O$. arbuscula is less abundant in habitats to which it is physiologically better suited, suggesting that biotic, rather than physiological, rigors may restrict its distribution on local scales.
\end{abstract}

KEY WORDS: Coral · Temperate · Oculina arbuscula $\cdot$ Feeding $\cdot$ Light · Temperature

\section{INTRODUCTION}

Most scleractinian coral species are restricted to tropical waters. The few that have adapted to temperate waters generally differ from their tropical counterparts in that (1) they do not contribute appreciably to the accretion of reef structure, and (2) they display plasticity in their associations with photosynthetic symbionts; colonies within a species can span the range from zooxanthellate (containing photosynthetic endosymbionts) to azooxanthellate (Szmant-Froelich \& Pilson 1984, Schuhmacher \& Zibrowius 1985). Tight physical association of symbiotic primary producers (zooxanthellae) and coral animal hosts has been thought to allow efficient cycling of nutrients (especially those excreted by the animal) and photosynthate energy (translocated from the zooxanthellae to the host). Such associations have traditionally been re-

- Present address: Dept of Marine Biology and Fisheries, Rosenstiel School of Marine and Atmospheric Science, Univ. of Miami, 4600 Rickenbacker Cswy, Miami, FL 33149, USA garded as mutually beneficial and even as necessary adaptations to the oligotrophic conditions characteristic of tropical waters (Muscatine \& Porter 1977), though this paradigm of mutualism is being revised (see Cook \& D'Elia 1987, Hinde 1988, and below)

Studies examining effects of external nutrient regimes on the mechanisms regulating the host-symbiont association and maintaining equilibrium zooxanthellae populations have produced conflicting results. Several studies have shown that elevating nitrogen concentration in the water increases zooxanthellae population density (Hoegh-Guldberg \& Smith 1989, Stambler et al. 1991, Stimson \& Kinzie 1991), suggesting a lack of symbiont population regulation by the host. In these situations, symbiont populations seem limited by the inorganic nitrogen available in the external environment. However, Szmant et al. (1990) observed very low zooxanthellae growth rates that they calculated could be supplied solely by small nitrogenous inputs from animal cell excretion. This result suggests that the animal host restricts zooxanthellae access to external nutrient sources. Belda et al. (1993), studying tridacnid 
clams and their photosynthetic symbionts, found evidence that hosts regulate phosphorus but not nitrogen availability to symbionts.

The current understanding of this paradox (Cook \& D'Elia 1987, Szmant et al. 1990, Falkowski et al. 1993) describes restriction of zooxanthellae growth by the animal host via nutrient limitation. The host must curb zooxanthellae population growth to a level below that allowed by photosynthetic capacity in order that excess fixed carbon remains available for translocation. Falkowski et al. (1993) suggest that under chronically elevated nutrient conditions, the host's restrictive mechanisms are ineffective and zooxanthellae populations escape host control (i.e. fixed carbon beyond the maintenance needs of the zooxanthellae is converted to more zooxanthellae, not translocated to the animal cell). In either case, nutrient acquisition, either absorbed directly from the water column or in the form of planktonic food consumed by the animal, plays an important role in productivity and balance between host and symbionts.

The relative importance of autotrophic versus heterotrophic nutrition in symbiotic corals has been long debated. As evidence for the importance of heterotrophy, previous authors stressed the effectiveness (Coles 1969) and complex structure of prey-capturing organs (Lewis \& Price 1975). More recently the strong influence of light on coral reproduction (Rinkevich 1989), calcification, growth, and primary production (Davies 1991) has been emphasized. Some authors have described scleractinian coral species as ranging over a trophic continuum with some species being primarily heterotrophic and others primarily autotrophic (Porter 1976, Wilkinson et al. 1988).

A previous study by Wellington (1982) used field manipulations of light and zooplankton to assess the autotrophic and heterotrophic contributions to growth in 3 tropical reef corals and to determine if nutritional differentiation between the species could account for the marked zonation of the species observed on Pacific Panamanian reefs. His findings included a dominant contribution of light to coral growth but significant zooplankton effects as well, including small interspecific variation in the contribution of zooplankton to coral growth. However, he concluded that differences in nutritional requirements between the species studied were insufficient to account for local distribution patterns and that ecological interactions (i.e. differential mortality induced by resident fishes) were the determining factors.

Bleaching, or loss of zooxanthellae, in most tropical corals is an indication of extreme physiological stress and is often followed by death, but many temperate scleractinia (including members of the genera Oculina, Astrangia, and Madracis) can persist and grow as heterotrophic pale or unpigmented (asymbiotic) colonies in deeper or poorly-lit habitats as well as darkly colored, symbiotic colonies in shallow, well-lit habitats (Reed 1982, Jacques et al. 1983, Schuhmacher \& Zibrowius 1985, M. W. Miller pers. obs.). Many temperate corals, then, appear to be facultatively (as opposed to obligately) associated with zooxanthellae since the association seems to break down in habitats of low light. With 1 exception, the north- to mid-Atlantic Astrangia danae (Jacques et al. 1983), the importance of light and feeding to growth and symbiosis in temperate corals is unknown.

Physical factors characteristic of temperate habitats have been suggested to account for the general restriction of hard corals and coral reef structures to tropical latitudes. Low and variable temperatures (Dana 1843, Jokiel \& Coles 1977) as well as higher nutrient concentrations that increase turbidity (Birkeland 1988) have been implicated in contributing to the restriction of corals and coral reefs on latitudinal (Crossland 1988), and smaller, spatial scales. Alternatively, Johannes et al. (1983) suggested that physical factors act only indirectly by altering the outcome of biotic interactions along the latitudinal gradient. They hypothesized that seaweeds competitively exclude corals at higher latitudes. Thus, biotic factors could be the primary restrictions on latitudinal distribution of coral reefs.

In this study, I used the scleractinian coral Oculina arbuscula, which is endemic to the warm temperate waters of North and South Carolina, to investigate the effects of temperature and nutritional manipulations on a temperate species that appears to be facultatively symbiotic. This study was designed to provide not only insight concerning the biology and symbiosis of an unstudied temperate species, but also to assess the relevance of latitudinally varying physical factors such as temperature, light, and planktonic food availability in explaining coral distribution on a local scale. Specifically, I conducted laboratory, microcosm, and/or field experiments to address the following questions: (1) what is the effect of winter and summer temperature on growth of a temperate coral in the lab and in the field; (2) how do light levels and a fixed experimental food supply (zooplankton) interact to affect coral growth and chlorophyll a (chl a) concentrations; (3) under field conditions, how does depth affect coral growth and chl a concentration of coral tissues; and (4) do these responses to physical factors help predict coral distribution between depths in the field, or does the distribution of coral suggest that biotic factors may be more important?

\section{METHODS}

Study organism. Oculina arbuscula is a scleractinian coral endemic to the inshore and nearshore hardbottom habitats of North and South Carolina, USA 
(Ruppert \& Fox 1988); it forms branching colonies up to $0.5 \mathrm{~m}$ in diameter. Colonies growing in well-lit habitats display a rusty brown coloration indicative of high concentrations of intracellular zooxanthellae; colonies occurring in dark habitats (e.g. under overhangs) are white, suggesting a relative lack of photosynthetic endosymbionts and a primarily heterotrophic mode of nutrition. Unpigmented colonies from these dark habitats nevertheless attain sizes similar to those of photosynthetic colonies growing in the light (M. W. Miller pers, obs.). In some cases, a single colony will have pigmented and unpigmented parts. For example, when growing on a vertical substrate, colonies often have coloration on the upper surfaces and are white on the lower, shaded surfaces.

Determination of seasonal growth rates in the field. Growth rates of Oculina arbuscula at Radio Island Jetty, near Morehead City, North Carolina, $\left(34^{\circ} 42^{\prime} \mathrm{N}, 76^{\circ} 41^{\prime} \mathrm{W}\right)$, were determined during summer-fall 1991 and during winter 1991-92. In each season I collected 4 to $5 \mathrm{~cm}$ long branches from separate symbiotic colonies of $O$. arbuscula growing at 2 to $3 \mathrm{~m}$ depth at Radio Island Jetty and transported them back to running seawater tanks at the University of North Carolina - Chapel Hill Institute of Marine Sciences in Morehead City. Each branch was blotted with paper towel to remove excess water, weighed, glued by the base to a small, numbered PVC plate (approx. $3 \times 3 \mathrm{~cm}$ ) using Oatey Epoxy Putty (Cleveland, OH, USA), and then returned to the field. The coral plates were attached with cable ties to galvanized nails driven into the substrate at a depth of $5 \mathrm{~m}$. Potentially competing benthic organisms were removed from the substrate prior to placement of the corals. Temperature was monitored weekly in summer-fall (temperature range 18 to $28^{\circ} \mathrm{C}$ ) and monthly in winter $\left(5\right.$ to $\left.19^{\circ} \mathrm{C}\right)$ using a $\mathrm{max} / \mathrm{min}$ thermometer. During the summer-fall season, 13 coral branches were grown for 11 wk (August to November) and in winter 10 corals were grown for 16 wk (November to March); the branches were then returned to the lab for re-weighing. Coral growth rates from each season were expressed as the percentage change in wet mass per week, and compared using a 2-sample Wilcoxon test to evaluate the hypothesis that coral growth rates in winter and summer are the same.

Temperature experiment. To determine if seasonal growth differences were attributable to temperature, a laboratory experiment was conducted from January to March 1992. The experiment was conducted in an indoor water table with a fluorescent light bank suspended $0.5 \mathrm{~m}$ above the table. The light bank contained 2 types of bulbs, Philip $110 \mathrm{~W}$ cool white (F48T12/CW/VHO) and Sylvania $115 \mathrm{~W}$ Gro-Lux
(F48T12/GRO/VHO) yielding photosynthetically active light levels of approximately $300 \mu \mathrm{E} \mathrm{m}^{-2} \mathrm{~s}^{-1}$ (as determined with a LiCor quantum sensor). The water table had 2 separate sections which served only as temperature baths; no water exchange occurred between the water table and the 10 containers housing corals in each section. One section mimicked winter temperatures, containing a continuous flow of water pumped from adjacent Bogue Sound at winter ambient temperature. The other section had standing seawater at room temperature $\left(24^{\circ} \mathrm{C}\right)$, approximating, but still lower than, summer ambient temperatures. The roomtemperature side also had an aquarium heater (with the thermostat set at room temperaturej and a circulating pump to minimize temperature variation within this treatment. Temperature in the 2 treatments was monitored daily and average temperature in the warm treatment $( \pm 95 \%$ confidence interval, $\mathrm{CI}$ ) was $23.8 \pm$ $0.58^{\circ} \mathrm{C}$ while temperature in the cold treatment was lower and more variable at $13.5 \pm 1.06^{\circ} \mathrm{C}$. Paired, preweighed coral branches (i.e. 2 pieces from the same colony) from Radio Island were glued to PVC plates as described above and placed in pairs of $1 \mathrm{l}$ plastic containers of seawater. The 10 pairs of containers (with 10 pairs of corals) were arranged symmetrically, one in the cold side of the water table and one in the warm side. The insides of the containers were scrubbed every other day and refilled with fresh seawater. Fresh seawater to be placed in the warm treatment dishes was equilibrated to that temperature before being placed in the containers. Approximately weekly, all corals were fed brine shrimp Artemia sp. nauplii from a pipette in an amount to coat their surface. The position of corals within each half of the water table was rotated 4 times during the experiment to reduce potential variance due to light or temperature differences across the water table.

After $12 \mathrm{wk}$, the corals were re-weighed and growth calculated as the percentage change in wet mass per week. Difference in growth between temperature treatments was determined using a Wilcoxon paired signed ranks test.

Microcosm trophic experiment. To evaluate the response of Oculina arbuscula to availability of light and food (potential for autotrophic and heterotrophic nutrition), an outdoor microcosm experiment was conducted during summer 1993. Coral branches were collected at a depth of $10 \mathrm{~m}$ from the upper deck of a sunken ship located approximately $5 \mathrm{~km}$ offshore from Atlantic Beach, North Carolina. A total of 120 coral branches from separate adult colonies were weighed and glued to PVC plates as described above and were randomly assigned to 1 of 6 treatment groups for a 2 -way $(3 \times 2)$ factorial experiment with 20 replicates per treatment. 
The experimental factors were light ( 3 levels) and opportunity for heterotrophic consumption (2 levels, fed every 4 to $6 \mathrm{~d}$ vs not fed). One fed coral and one non-fed coral were placed together in each of 60 outdoor PVC (opaque) tanks of approximately $11 \mathrm{l}$ capacity. Each tank had an individual seawater inlet and outlet with continuous flow of gravel-filtered seawater pumped from adjacent Bogue Sound.

The 3 light levels used were 1, 25, and $100 \%$ ambient irradiance as measured by a LiCor Spherical Quantum Sensor, Model LI-193SB. Light treatments were effected by covering the individual tanks with 2 layers of black plastic (from Kordite trash bags, Mobile Chemical Co., Pittsford, NY, USA) for the $1 \%, 2$ layers of black plastic mesh screening for the $25 \%$, or leaving the top open for the $100 \%$ ambient treatment. To prevent undue stress from light shock, corals assigned to the full exposure treatment were acclimated during the first week of the experiment by successive removal of layered mesh shades; beginning with 3 and removing 1 every other day.

The feeding treatment was conducted every 4 to $6 \mathrm{~d}$ by individually enclosing corals that were to be fed in a $0.5 \mathrm{l}$ plastic container with a lid, adding a $20 \mathrm{ml}$ aliquot (equal to $15.6 \pm 2.76 \mathrm{mg}$ dry wt of food, mean $\pm 95 \% \mathrm{Cl}, \mathrm{n}=14$ ) from a standard culture of Artemia sp. nauplii hatched from commercially available eggs, and allowing them to feed for 2 to $6 \mathrm{~h}$. Control corals were enclosed at the same time in identical containers, but without Artemia sp. Enclosure in a small volume of water facilitated consumption by the fed corals and allowed the placement of fed and non-fed treatments in a single tank. The closed containers remained in the flow-through tanks during feedings to maintain constant light and temperature conditions. Thus, there were 120 corals paired in 60 tanks constituting 20 independent replicates for each of the 6 treatments.

The experiment ran for $6 \mathrm{wk}$ (mid May to late June) after which the corals were re-weighed and their growth expressed as percent change in wet mass. Random sub-samples ( $n=3$ for each treatment) were then analyzed for chl a concentrations to determine if the various treatments affected pigment concentration and, thus, photosynthetic potential. A tip from each coral (6 to 11 polyps) was removed with wire cutters and extracted in $5 \mathrm{ml} 90 \%$ acetone in the dark at $2^{\circ} \mathrm{C}$ for $72 \mathrm{~h}$. Samples were then diluted to $4 \%$ of original concentration with $90 \%$ acetone and read on a Turner Fluorometer (Model 111). Total chl a (in $\mu \mathrm{g}$ ) in each sample was calculated according to a calibration regression. This mass of chl a was then expressed as $\mu \mathrm{g}$ per polyp in the original coral fragment that had been extracted.
Coral growth and chlorophyll concentration data were analyzed by 2-way ANOVA using SAS PROC GLM after examination of potential heteroscedasticity via an $F_{\text {max }}$-test.

Field experiment. From the sunken ship site, both pigmented (i.e. brown, from exposed surfaces) and unpigmented (i.e. white, from under overhangs, vertical surfaces, etc.) coral branches were collected from a depth of about $10 \mathrm{~m}$ for use in a factorial field experiment designed to examine the effect of depth and pigment state on Oculina arbuscula growth in the field. Corals were marked individually by tying to each a very small (approx. $6 \times 3 \mathrm{~mm}$ ) individually numbered fish tag (Floy Tag Co, Seattle, WA, USA) using clear nylon thread. The corals were weighed as described above and then placed in various treatment combinations in the field at Radio Island Jetty. Corals were cable-tied directly to galvanized nails that had been driven into jetty rocks. Potentially competing sessile invertebrates and seaweeds had been removed from the rocks prior to placement of the corals.

Both pigmented and unpigmented corals were placed at 2 depths, $1 \mathrm{~m}$ and $6 \mathrm{~m}$. After $6 \mathrm{wk}$ in the field (early August to late September), corals were collected, re-weighed to determine growth, and tips from all were extracted to determine chl a concentrations at the end of the experiment (procedure as described above). Data were analyzed by ANOVA and ANCOVA. Unequal sample sizes of treatment combinations resulted from breakage and mortality of coral pieces so significance tests were performed using the Type III mean-square estimates provided by PROC GLM of SAS for unbalanced data (SAS Inst. 1985).

Field distribution. To assess the concordance of experimental results on conditions promoting improved coral growth with the natural distribution of the coral, sampling of Oculina arbuscula was conducted in September 1992 at Radio Island Jetty and in November 1992 at Cape Lookout Jetty, North Carolina. At each site, 2 transects were run, one along the upper ( 2 to $3 \mathrm{~m}$ depth) and one along the lower portion of the jetty (5 to $6 \mathrm{~m}$ depth). A total of 15 (Cape Lookout) or 26 (Radio Island) $0.25 \mathrm{~m}^{2}$ quadrats were sampled at $3 \mathrm{~m}$ intervals along each transect. In each quadrat, the number of coral colonies was determined and, using a $10 \times 10$ random grid of monofilament strung within the quadrat, the percent cover of seaweeds was estimated by counting the number of grid points (100 total) lying over seaweed thalli. Data were analyzed for differences in abundance between depths using 2-sample $t$-tests, and correlation between coral and seaweed abundance was calculated. 


\section{RESULTS}

\section{Seasonal growth rates}

In the field, Oculina arbuscula grew about 4 times faster in summer than in winter $(2$-tailed $p<0.0026$, Wilcoxon 2 -sample test, $\mathrm{n}=10$ to 13). There was, however, no significant difference in mortality between corals grown in summer and in winter, and average winter growth rates were still positive (Fig. 1A).

\section{Temperature experiment}

In the lab, corals held in $24^{\circ} \mathrm{C}$ water grew significantly faster (Fig. 1B) than those held in water at ambient winter temperature of about $13^{\circ} \mathrm{C}$ (2-tailed $\mathrm{p}=0.027$, Wilcoxon paired signed ranks test, $\mathrm{n}=10$; Fig. 1B). As in the field experiment, growth of Oculina arbuscula at winter ambient temperatures was positive. Growth at winter temperatures in the lab was very similar to winter growth in the field (about $0.5 \%$ $w^{-1}$, Fig. 1A, B). Holding corals in the lab at summer temperatures increased growth over winter temperatures but achieved only about half the rate observed under summer field conditions (Fig. 1A, B).

\section{Microcosm trophic experiment}

Oculina arbuscula maintained positive average growth rates in all treatments except the treatment

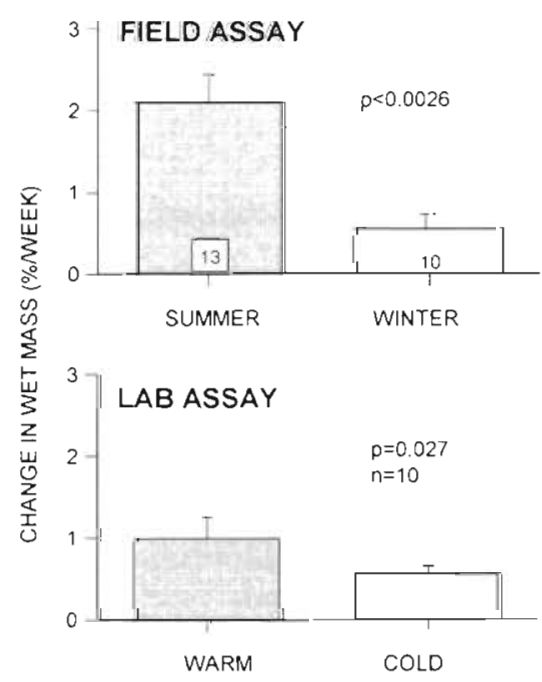

Fig. 1. Oculina arbuscula. Comparison of growth rates of corals transplanted into the field at Radio Island Jetty, North Carolina, USA, during summer (August to November) and winter (November to March) using a Wilcoxon 2-sample test and in the lab at winter ambient and room temperature using a Wilcoxon paired signed ranks test. Bars represent means $\pm 1 \mathrm{SE}, \mathrm{p}$-values are 2 -sided. Sample size is given above or within bars
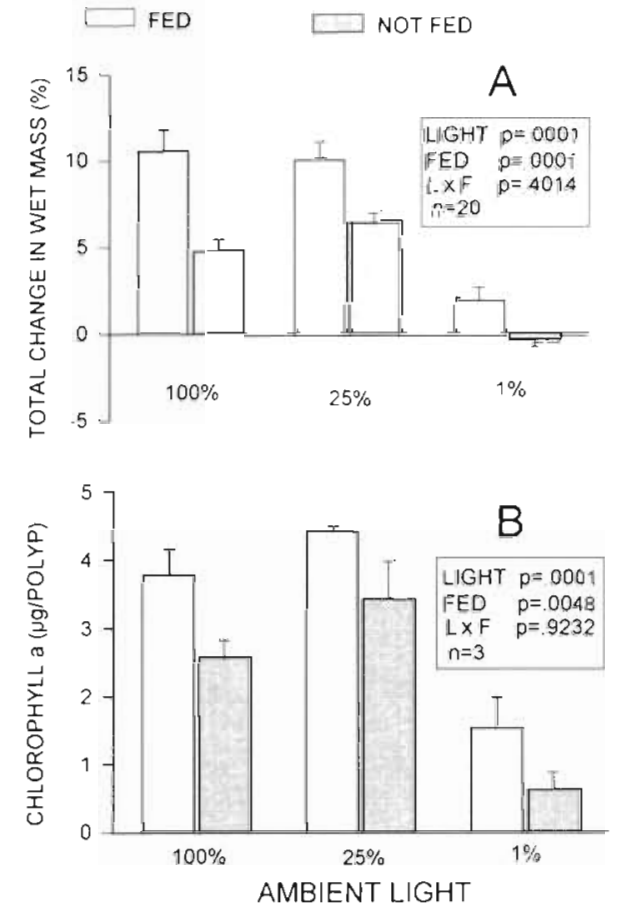

Fig. 2. Oculina arbuscula. (A) Growth and (B) final chl a concentrations of a subsample of corals in microcosms after $6 \mathrm{wk}$ under various light conditions with and without supplemental feeding. Bars represent means $\pm 1 \mathrm{SE}, \mathrm{p}$-values are from 2-way ANOVAs, in (A) based on transformed growth data (see lext)

involving denial of both light and supplemental food (Fig. 2A). The coral growth data exhibited heterogeneous variances and so were arcsin transformed, requiring the addition of a constant $(4 \%$, equal to the greatest negative growth value) to all growth data to eliminate negative numbers. Variances for the transformed data were homogeneous $\left(F_{\max }=2.39, k=6\right.$, $\mathrm{n}=20, \mathrm{p}>0.05)$ A 2-way ANOVA showed significant effects of both light and feeding $(p=0.0001$ for each, Fig. 2A shows actual, untransformed data) on the growth of $O$. arbuscula with no significant interactive effects. Overall, light and heterotrophy appear to have approximately additive effects on coral growth. Corals deprived of both displayed no mortality over the $6 \mathrm{wk}$ of this experiment but did exhibit slightly negative average growth.

Chl a concentrations for the 6 treatment groups showed a similar pattern to that of growth rates (Fig. 2B). Again 2-factor ANOVA showed both light $(p=0.0001)$ and feeding $(p=0.0048)$ to have significant influence on chl a concentration in the coral tissue, with no significant interaction. Corals grown in $1 \%$ light displayed lower chl a. However, provision of a supplemental food source (Artemia sp.) was associated with generally higher levels of pigment. 


\section{Field experiment}

In the field, coral growth was significantly greater at a depth of $1 \mathrm{~m}$ than at a depth of $6 \mathrm{~m}$ (Fig. 3A). After arcsin transformation to improve modest heterogeneity of variances, I performed a 2-way ANOVA using depth and initial pigment state (pigmented or unpigmented) as the factors. This analysis showed that depth had a significant effect $(p=0.0062)$ on coral growth. Colonies that were initially unpigmented (white) did not significantly differ in growth over the course of the experiment from those that were initially brown (Pigment, $p>0.15)$, and there was no significant interaction of depth and pigmentation.

When the corals were retrieved at the end of the experiment I found that, for many, the degree of pigmentation had changed from the beginning of the experiment. Corals in the shallow, 'unpigmented' treatment had gained pigment and the pigmented colonies in the deep treatment had noticeably paled. Thus, statistical comparisons were also performed using ending chl a concentrations.

The correlation of growth with ending chl a concentration was significant $(r=0.5496, p=0.0009)$, and means of these ending chl a concentrations among treatments mirrored the pattern for growth rates
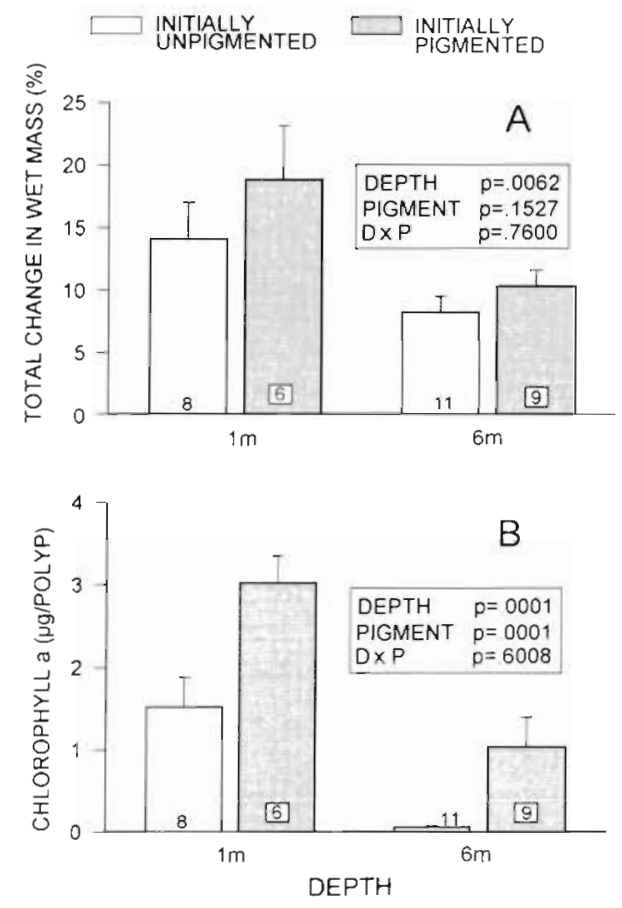

Fig. 3. Oculina arbuscula. (A) Growth and (B) final chl a concentrations of initially heavily pigmented and of initially white colonies grown for 6 wk at different depths in the field. Error bar represents mean $\pm 1 \mathrm{SE}, \mathrm{p}$-values for the chlorophyll data based on 2-way ANOVA for transformed data (see text). Sample size for each group is given within each bar
(Fig. 3A, B). Two-factor ANOVA showed coral chl a concentrations (after square-root transformation to improve severe heterogeneity of variances yielding $F_{\max }=17.9, k=4, \mathrm{n}=6$ to $11,0.01<\mathrm{p}<0.05$ ) to be significantly affected by depth as well as by their pigment state at the beginning of the experiment $(\mathrm{p}=0.0001$ for both), with no significant interaction (Fig. 3B).

I used ANCOVA in an attempt to investigate alternative causal models for the observed influence of light or depth on both coral growth and chl a concentrations. In the first case, chl a may be the mechanism by which growth is affected by light or depth. The ANCOVA for this scenario assumed that growth (dependent or response variable, $Y$ ) is dependent on chl a concentration (independent covariate, $X$ ) and sought to determine the differences between depth treatments that would have been observed for a fixed level of chl a concentration (Sokal \& Rohlf 1981). This ANCOVA with interaction showed no significant effect of depth $(F=0.2, \mathrm{df}=1, \mathrm{p}=0.659)$ and no significant interaction of depth and chl a $(F=1.27$, df $=1, p=0.2687)$. The covariate, ending chl a concentration, was significant $(F=5.07, \mathrm{df}=1, \mathrm{p}=0.0318)$. When the interaction term is dropped from the model, depth remains nonsignificant $(F=0.93, \mathrm{df}=1, \mathrm{p}=0.343)$. Thus, under the assumptions of this regression model, if chl a concentration could be fixed, coral growth would not have significantly differed between depths.

Alternatively, fast-growing corals may simply be able to accumulate more chl $a_{\text {, }}$ in which case higher chl a would be an effect, not a cause of high growth rate. An ANCOVA model having growth as the independent covariate could seek to determine the difference in chl a concentration between depth groups if growth could have been held constant. This analysis shows the depth groups do differ in chl a concentration ( $F=5.31, \mathrm{df}=1, \mathrm{p}=0.0283$ ) even when differences in growth rate are accounted for. Significance of the depth effect increases to $p=0.0006$ when the insignificant $(p=0.6445)$ interaction term is removed from this model.

\section{Field distribution}

In examining the natural distribution of Oculina arbuscula, I found it to be significantly more abundant along the deeper transects than along the shallower transects at Cape Lookout $(\mathrm{p}=0.001)$ and Radio Island $(p=0.05)$ Jetties. Seaweed cover showed the opposite trend, averaging $50 \%$ and $78 \%$ cover in the shallow quadrats at the 2 sites, respectively, and only $17 \%$ and $0 \%$ cover in the deep quadrats (Fig. 4A, B). The correlation between coral and seaweed abundance at Cape Lookout across depths was $r=-0.49(p=0.0086$, 

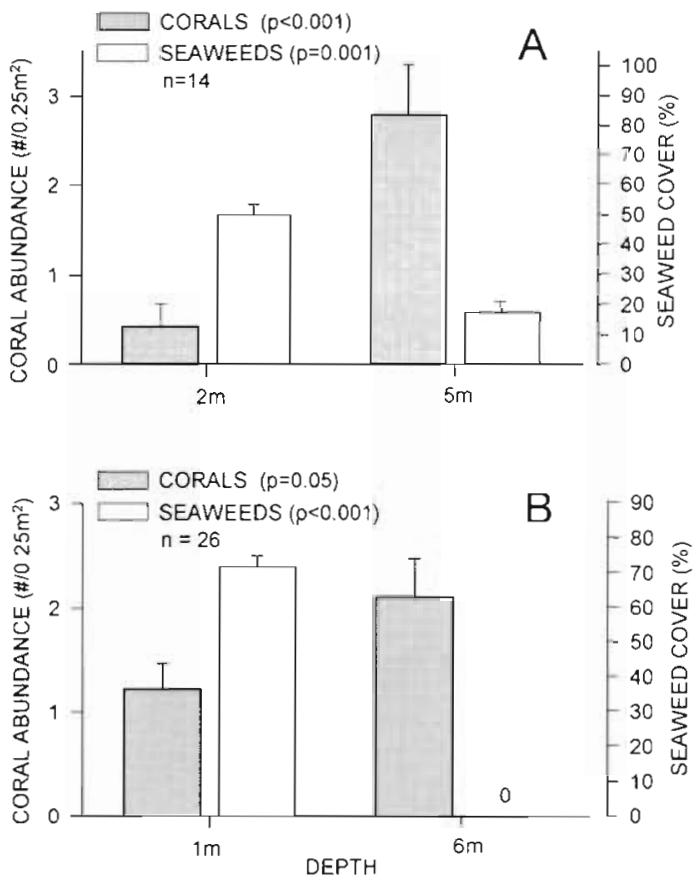

Fig. 4. Oculina arbuscula. Mean abundance of corals (no. per $0.25 \mathrm{~m}^{2} \pm 1 \mathrm{SE}$ ) and seaweeds (\% cover $\pm 1 \mathrm{SE}$ ), deep and shallow, at (A) Cape Lookout and (B) Radio Island Jetties; p-values from 2-sample $t$-tests

$\mathrm{n}=28$ ). At Radio Island, seaweeds were only present on the shallow transect and the correlation in quadrats from that transect was $\mathrm{r}=-0.48(\mathrm{p}=0.01, \mathrm{n}=26)$.

\section{DISCUSSION}

Oculina arbuscula showed broad tolerance to temperature and trophic conditions in these lab and field experiments, as might be expected for a species occurring in temperate habitats. However, the highest growth rates were observed under conditions of warm temperature and high light, conditions more characteristic of tropical than temperate waters. The depressed growth under laboratory (versus field) conditions observed when temperatures were warm (i.e. when growth potential was high; Fig. 1) was probably due to the fact that corals were in standing water in the lab, and had access to only limited food supplements.

Oculina arbuscula illustrated great plasticity in nutritional mode by maintaining positive growth rates under both primarily heterotrophic (fed in 1\% light. treatment) and primarily autotrophic (not fed in 25\% and $100 \%$ light treatments) conditions. However, the highest growth rates in the microcosm experiment were observed when the corals utilized both heterotrophic and autotrophic nutritional sources. The unquantified but possibly small amount of zooplankton consumption in the fed treatments (above the undetermined levels of background organics present in the gravel-filtered water) appeared to stimulate an additional 3\% (1\% light level) to $6 \%$ (25 and 100\% light levels) increase in coral mass. The lack of significant interaction in the ANOVA suggests that the effects of light and feeding (at the levels/frequencies performed in this experiment) are approximately additive.

Chl a concentrations also appear to be very plastic since, when either light or food was reduced, chl a concentrations were reduced (Fig. 2B) and unpigmented corals placed in shallow (lighted) field conditions appeared to gain pigments (Fig. 3B). Zooxanthellae density was not measured directly in this study, and chl a concentration within zooxanthellae cells can vary by a factor of 3 or more according to light conditions. However, dinoflagellates in general (Prezelin 1987) and zooxanthellae in particular (Gattuso 1985, Porter et al. 1984, Dubinski \& Jokiel 1994) are known to display increased chl a concentrations per cell under low, not high light conditions. The current study, showing increased chl a per polyp of coral tissue with light and decreased concentrations with depth, thus suggests alterations in zooxanthella density, not altered pigment concentrations per zooxanthella cell. Feeding (Szmant-Froelich \& Pilson 1980, Cook et al. 1988) as well as enriched nutrient concentrations in the water column (e.g. Hoegh-Guldberg \& Smith 1989) have also been shown to stimulate zooxanthellae density.

Thus, if chl a per polyp is taken to be an indicator of zooxanthellae concentration, the positive association of chl $a$ and coral growth observed in both the microcosm and the field experiments is consistent with either active expulsion by the host when the metabolic costs of zooxanthellae exceed their benefit to the animal host or passive limitation of zooxanthellae numbers under conditions of carbon (light) and/or nutrient (food) shortage. In any case, both zooxanthellae and coral populations seem most fit in environments providing both light and planktonic food, and Oculina arbuscula is not able to foster increased photosynthetic capacity in its symbiont population (increasing $\mathrm{chl}$ a concentration) to compensate for reduced heterotrophic intake.

Because this study used a single, low frequency level of feeding, it does not address the capacity for Oculina arbuscula to compensate for lack of photosynthesis by increased heterotrophic consumption. Experiments by Clayton \& Lasker (1982) found reduced, not increased, consumption rates by the tropical coral Pocillopora damicornis when kept in the dark, contradicting the possibility of compensation by feeding. Nothing is known about food availability and consumption rates for $O$. arbuscula in the field, but the occurrence of $O$. arbuscula in dark habitats in the field (such as under 
overhangs or inside wrecks; author's pers. obs.) indicates that it can consume enough heterotrophically for maintenance and growth, though perhaps at slower rates than in the light. In fact, Reed (1982) reports that a congeneric species, $O$. varicosa, occurring in Florida has higher growth rates in asymbiotic colonies that grow at $80 \mathrm{~m}$ depth than in symbiotic colonies that grow at $6 \mathrm{~m}$ depth. The asymbiotic $O$. varicosa forms reef-like thicket structures at $80 \mathrm{~m}$.

It is likely that the $100 \%$ and $25 \%$ light levels used in the microcosm experiment are significantly higher than those experienced by Oculina arbuscula in the field because most colonies occur in deeper habitats (Fig. 4). Also, these trophic experiments were conducted at summer ambient temperatures of over $20^{\circ} \mathrm{C}$. Jacques et al. (1983) examined rates of production and calcification in pigmented and unpigmented colonies of another temperate coral, Astrangia danae, collected in Narragansett Bay, Rhode Island, USA, under varying conditions of light and temperature. They found photosynthesis to be reduced and calcification and coral growth to be dependent on heterotrophic consumption at temperatures below $15^{\circ} \mathrm{C}$. At temperatures below $6^{\circ} \mathrm{C}$, feeding and growth both ceased. If these temperature thresholds are realistic, or conservatively low for the more southern $O$. arbuscula, heterotrophic consumption could be more important to $O$ arbuscula growth during much of the year even when light is available since, in North Carolina inshore waters, temperatures are consistently below $15^{\circ} \mathrm{C}$ for 3 to 4 mo per year but rarely below $6^{\circ} \mathrm{C}$ (Sutherland \& Karlson 1977).

In both microcosm (Fig. 2) and field (Fig. 3) experiments, coral growth rates and final chl a concentrations are directly related and show identical relative rankings among treatment groups. My experiments cannot definitively distinguish the alternative explanations (1) that high light (photosynthetic potential) stimulates higher chl a concentrations yielding higher coral growth rates, or (2) that at higher growth rates (due to shallow depth, high light levels, or consumption of planktonic food), corals may be able to foster more pigment accumulation. In the latter case high chl a concentrations could be viewed as an effect, not a cause, of high growth. The alternative ANCOVAs from the field experiment support the first alternative since differences in growth between depths can be accounted for by variation in chl a concentrations whereas differences in chl a concentrations between depths are not satisfactorily accounted for by variation in growth.

The improved growth of Oculina arbuscula at shallow depth (Fig $3 \mathrm{~A}$ ) is consistent with observations of growth rates of tropical corals in the field (e.g. Huston 1985) and with the results from the microcosm experiment (Fig. 2A) in that light intensity and coral growth both decrease with depth. From these results we would predict $O$. arbuscula to be more abundant in shallow, well-lit, as opposed to deeper and darker habitats. At both Cape Lookout and Radio Island Jetties, this prediction is not correct (Fig, 4). Similar paradoxical distributions (i.e. greater population densities in habitats with lesser growth potential) have been documented for other marine benthic invertebrates including bivalves (Peterson \& Black 1988) and barnacles (Connell 1961). In all these instances, zonation patterns are strongly influenced by biotic factors, so it cannot be assumed that high population densities indicate physiologically beneficial habitats without experimental confirmation. In the current study, responses to the physical habitat are insufficient to explain the observed distribution of a temperate coral on local scales. Rather, it appears that some other factor is restricting $O$. arbuscula from its more favorable physical habitats (i.e. shallow areas of jetties), and the disjoint distribution of seaweeds with corals appears to be consistent with Johannes et al.'s (1983) hypothesis that seaweed competition may limit corals at high latitudes. Experimental manipulation is required to test this hypothesis

Acknowledgments. Financial support for this project was provided by a Sigma Xi Grant-in-aid of Research and by NSF Grant OCE 92-02847 and NOAA/NURC grants UNCW9209 and UNCW9308 to Mark E. Hay. Facilities were provided by the University of North Carolina at Chapel Hill Institute of Marine Sciences. Mark Hay and Seth Reice provided invaluable support and advice. Jay Pinkney assisted in the pigment analyses. The manuscript was greatly improved by comments from Mark Hay, Phil Levin, and several anonymous reviewers.

\section{LITERATURE CITED}

Belda CA, Lucas JS, Yellowlees D (1993) Nutrient limitation in the giant clam-zooxanthellae symbiosis: effects of nutrient supplements on growth of the symbiotic partners. Mar Biol 117:655-664

Birkeland C (1988) Geographic comparisons of coral-reef community processes. Proc 6th Int Coral Reef Symp 1: $211-220$

Clayton WS, Lasker HR (1982) Effects of light and dark treatments on feeding by the reef coral Pocillopora damicornis (Linnaeus). J exp mar Biol Ecol 63:269-279

Coles SL (1969) Quantitative estimates of feeding and respiration for three scleractinian corals. Limnol Oceanogr 14 : 949-953

Connell JH (1961) The influence of interspecific competition and other factors on the distribution of the barnacle Chthamalus stellatus. Ecology 42:710-723

Cook CB, D'Elia CF (1987) Are natural populations of zooxanthellae ever nutrient-limited? Symbiosis 4:199-212

Cook CB, D'Elia CF, Muller-Parker G (1988) Host feeding and nutrient sufficiency for zooxanthellae in the sea anemone Aiptasia pallida. Mar Biol 98:253-262 
Crossland CJ (1988) Latitudinal comparisons of coral reef structure and function. Proc 6th Int Coral Reef Symp 1: $221-226$

Dana JD (1843) On the temperature limiting the distribution of corals. Am J Sci 45:130-131

Davies PS (1991) Effects of daylight variations on the energy budgets of shallow water corals. Mar Biol 108:137-144

Dubinski Z, Jokiel PL (1994) Ratio of energy and nutrient fluxes regulates symbiosis between zooxanthellae and corals. Pacif Sci 48:313-324

Falkowski PG, Dubinsky Z, Muscatine L, McCloskey L (1993) Population control in symbiotic corals. BioSci 43(9):606-611

Gattuso JP (1985) Features of depth effects on Stylophora pistillata, an hermatypic coral in the Gulf of Aqaba (Jordan, Red Sea). Proc 5th Int Coral Reef Congr 6:95-100

Hinde R (1988) Symbiotic nutrition and nutrient limitation Proc 6th Int Coral Reef Symp 1:199-204

Hoegh-Guldberg O, Smith GJ (1989) Influence of the population density of zooxanthellae and supply of ammonium on the biomass and metabolic characteristics of the reef corals Seratopora hystix and Stylophora pistillata. Mar Ecol Prog Ser 57:173-186

Huston MA (1985) Variation in coral growth rates with depth at Discovery Bay, Jamaica. Coral Reefs 4:19-25

Jacques TG, Marshall N, Pilson MEQ (1983) Experimental ecology of the temperate scleractinian coral Astrangia danae. Mar Biol 76:135-148

Johannes RE, Weibe WJ, Crossland CJ, Rimmer DW, Smith SV (1983) Latitudinal limits to coral reef growth. Mar Ecol Prog Ser 11:201-208

Jokiel PL, Coles SL (1977) Effects of temperature on the mortality and growth of Hawaiian reef corals. Mar Biol 43: 201-208

Lewis JB, Price WS (1975) Feeding mechanisms and feeding strategies of Atlantic reef corals. J Zool Lond 176:527-544

Muscatine L, Porter JW (1977) Reef corals: mutualistic symbioses adapted to nutrient-poor environments. BioSci $27(7): 454-460$

Peterson CH, Black R (1988) Responses of growth to elevation fail to explain vertical zonation of suspension-feeding bivalves on a tidal flat. Oecologia 76:423-429

Porter JW (1976) Autotrophy, heterotrophy, and resource partitioning in Caribbean reef corals. Am Nat 110(975): $731-742$

Porter JW, Muscatine L, Dubinski Z, Falkowski PG (1984) Primary production and photoadaptation in light- and shade-adapted colonies of the symbiotic coral Stylophora

This article was presented by C. H. Peterson (Senior Editorial Advisor), Morehead City, N. Carolina, USA. pistillata. Proc R Soc London B 222:161-180

Prezelin BB (1987) Photosynthetic physiology of dinoflagellates. In: Taylor FJR (ed) The biology of dinoflagellates. Blackwell Scientific Publishing, Oxford, p 174-223

Reed JK (1982) In situ growth rates of the scleractinian coral Oculina varicosa occurring with zooxanthellae on $6 \mathrm{~m}$ reefs and without on $80 \mathrm{~m}$ banks. Proc 4 th Int Coral Reef Symp 2:201-206

Rinkevich B (1989) The contribution of photosynthetic products to coral reproduction. Mar Biol 101:259-263

Ruppert EE, Fox RS (1988) Seashore animals of the Southeast Univ of South Carolina Press, Columbia

SAS Inst (1985) SAS users guide: statistics, Version 5 edition. SAS Inst, Inc, Cary, NC

Schuhmacher $\mathrm{H}$, Zibrowius $\mathrm{H}$ (1985) What is hermatypic? A redefinition of ecological groups in corals and other organisms. Coral Reefs $4: 1-9$

Sokal RR, Rohlf FJ (1981) Biometry. WH Freeman and Co, NewYork

Stambler N, Popper N, Dubinski Z, Stimson J (1991) Effects of nutrient enrichment and water motion on the coral Pocillopora damicornis. Pacif Sci 45(3):299-307

Stimson J, Kinzie RA III (1991) The temporal pattern and rate of release of zooxanthellae from the reef coral Pocillopora damicornis (Linnaeus) under $\mathrm{N}$-enrichment and control conditions. J exp mar Biol Ecol 153:63-74

Sutherland JP, Karlson RH (1977) Development and stability of the fouling community at Beaufort. NC. Ecol Monogr 47:425-446

Szmant A, Ferrer LM, FitzGerald LM (1990) Nitrogen excretion and $O: N$ ratios in reef corals: evidence for conservation of N. Mar Biol 104:119-127

Szmant-Froelich A, Pilson MEQ (1980) The effects of feeding frequency and symbiosis with zooxanthellae on the biochemical composition of Astrangia danae Milne Edwards \& Haime 1848. J exp mar Biol Ecol 48:85-97

Szmant-Froelich A, Pilson MEQ (1984) Effects of feeding frequency and symbiosis with zooxanthellae on nitrogen metabolism and respiration of the coral Astrangia danae. Mar Biol 81:153-162

Wellington GM (1982) An experimental analysis of the effects of light and zooplankton on coral zonation. Oecologia 52:311-320

Wilkinson CR, Cheshire AC, Klumpp DW, McKinnon AD (1988) Nutritional spectrum of animals with photosynthetic symbionts - corals and sponges. Proc 6th Int Coral Reef Symp 3:27-30

Manuscript first received: May 10, 1994

Revised version accepted: January 18, 1995 